\title{
Tecnologia da Informação para Gestão do Conhecimento em Organização Virtual
}

\author{
Luiz Antonio Joia \\ Professor Adjunto da Faculdade de Engenharia \\ Universidade do Estado do Rio de Janeiro - Uerj \\ E-mail: joia@uerj.br
}

Resumo

Esse artigo apresenta uma modelagem para integrar eficazmente diferentes tecnologias da informaçāo de modo a aumentar a inteligência de organizaçōes virtuais. O conceito de inteligência para uma organização virtual é analisado e as tecnologias da informaçăo necessárias para a criação desse ambiente de negócios apresentadas, assim como um modelo integrador baseado na taxonomia tecnologia-serviços-processos-produçāo. Os maiores obstáculos e problemas para se obter uma organizaçāo virtual inteligente sāo descritos, assim como soluçōes para solucionar a questāo. Tendências futuras e conclusōes em relaçāo a essa área de pesquisa sāo também apresentadas.

\section{Abstract}

This article presents a framework to integrate effectively different Information Technologies in order to raise the intelligence of Virtual Organizations. The concept of intelligence in a Virtual Organization is analyzed and the information technologies needed to create this business environment are presented, as well as an integrated model based on a technology-service-process-production taxonomy. The main obstacles and hurdles to accomplish an intelligent Virtual Organization are presented as well as the solutions to overcome them. Future trends and some conclusions in this realm are still presented.

\section{Palavras Chaves:}

Tecnologia da Informação; Gestão do Conhecimento; Organização Virtual; Inteligência Empresarial; Sociedade do Conhecimento.

\section{Keywords:}

Information Technology, Knowledge Management, Virtual Organization, Knowledge Society.

\section{Introdução}

Em 1994, a Sloan School of Management do MIT inaugurou um programa de pesquisa denominado: "Inventando as Organizações para o século XXI", dirigido por Thomas Malone, Diretor do Centro de Ciências da Coordenação. Uma das atividades principais dessa pesquisa tem sido o desenvolvimento de prováveis cenários para as organizações futuras. Um grupo de trabalho formado, considerando uma enorme variedade de forças, variantes e incertezas que poderiam moldar as organizações do século XXI, traçou dois possíveis cenários envolvendo o tamanho e o modus operandi das futuras organizações: "Pequenas Empresas, Grandes Redes", como as organizações encontradas no Norte da Itália (região textil do Prato), e "Países Virtuais", à medida que mais e mais fusões e aquisições têm ocorrido no cenário mundial (p.ex. Exxon e Mobil) (Laubacher \& Malone, 1997).

Um dos maiores desafios da Economia do Conhecimento é lidar com novas formas organizacionais, i.e., com aquelas que desafiam as 
PRODUÇÃO

nocões tradicionais de estrutura, coordenação e controle, tal qual acontece no cenário "Pequenas Empresas, Grandes Redes". Quando todos os processos e tarefas de um empreendimento são centralizados em apenas uma companhia não é difícil a gestão do conhecimento derivado de determinado projeto. Entretanto, quando uma variedade de parceiros é envolvida em um único empreendimento, a questão reside em: como criar, armazenar e gerenciar o conhecimento gerado durante um projeto, de modo a que ele não seja perdido e possa ser usado em projetos futuros?

Alguns trabalhos importantes têm sido geradas sobre esse tema, tais como: "Knowledge Links", Badaracco J., em The Knowledge Link: How Firms Compete Through Strategic Alliances, 1991, Harvard Business School Press; "The Emerging Flexible Organization: Perspectives from Silicon Valley", Bahrami, H., California Management Review, Vol.34, No. 4, 1992; "Building Intelligent Networks", Baker W., em Networking Smart, capítulo 3, 1994, McGrawHill, Inc., apenas para citar alguns.

Não obstante muito importantes em suas áreas, essas pesquisas apenas tangenciam a questão relacionada a como criar, implantar, transferir, armazenar e recuperar a inteligência de um empreendimento envolvendo diferentes empresas geograficamente dispersas, com distintas - porém importantes -, responsabilidades. Dessa forma, o próximo passo lógico inclui a expansão dessas pesquisas para ambientes inter-organizacionais. De modo a atingir esse objetivo, mister se torna a compreensão de como a Tecnologia da Informação pode fortalecer e aumentar os "links" de conhecimento entre os envolvidos num grande empreendimento.

\section{Objetivos}

Uma organização virtual é uma quasi-firma criada a partir de ligações digitais entre várias companhias, de tal forma que é quase impossível se determinar seus limites (Keen, 1991). Uma organização virtual é independente de sua estrutura organizacional, já que cada nó da rede tem sua própria estrutura que pode ser modificada sem interferir nas estruturas organizacionais dos outros nós.

"A organização é sua estrutura formal" e "A estrutura segue a estratégia" são duas hipóteses desafiadas pelo ambiente das organização virtuais que, inteligentemente, usam a tecnologia da informação (Keen, 1991).

O principal objetivo desse artigo é integrar eficazmente diferentes tecnologias da informação para aumentar a inteligência de uma organização virtual responsável por grandes empreendimentos, através da criação, implantação, compartilhamento, armazenamento e recuperação tanto do conhecimento tácito como do explícito.

Esse estudo analisa o papel e impacto das tecnologias da informação em três áreas de uma organização virtual: seu grau de conectividade, seu grau de compartilhamento e seu grau de estruturação. Esses três parâmetros são considerados vitais para estabelecer a inteligência de uma organização virtual e sua capacidade de gerir o conhecimento envolvido.

A conectividade relaciona-se com o "grau de alcance" de uma organização virtual, i.e., se e como as companhias envolvidas estão conectadas dentro do ambiente virtual, de modo a transmitir dados e informações entre si.

O compartilhamento analisa o "grau de abrangência" de uma organização virtual, i.e, os tipos de transações desenvolvidos dentro da organização virtual, e o modo pelo qual as empresas 
trabalham juntas, de modo a criar-se um ambiente colaborativo.

Finalmente, a estruturação lida com a habilidade que as empresas têm em extrair conhecimento a partir de dados e informações recebidas e compartilhados entre si. Como é sabido, conhecimento - seja tácito ou explícito - é muito mais do que dados e informação e, de acordo com a Teoria da Autopoiesis (Maturana \& Varela, 1980), é criado quando um "acoplamento estrutural" ocorre com os trabalhadores. Este trabalho mostra que esse parâmetro é o ponto-chave para o sucesso de um empreendimento, e aquele que menos desenvolvido se encontra dentro das empresas. As pessoas têm uma grande dificuldade em transformar dados brutos e informação em conhecimento, não obstante vários modelos terem sido desenvolvidos, como a "Espiral do Conhecimento" de Nonaka \& Takeuchi, 1995. O sistema educacional atual impede os trabalhadores de aprender a aprender, tornando dificil que eles não criem modelos mentais rotinizados para lidar com algum conhecimento novo.

A partir daí, diferentes tecnologias tais como EDI (Troca Eletrônica de Dados), EDMS (Sistema de Gerenciamento de Documentação Eletrônica), Sistemas de Workflow, Internet/intranet/ extranet e principalmente IBW (Instrução Baseada na WEB), apenas para citar algumas, são integradas para aumentar a inteligência de uma organização virtual.

Analisa-se a literatura organizacional sobre desenvolvimento do conhecimento para identificação dos desafios associados com processos não coordenados e dispersos dentro de um mesmo empreendimento. A seguir, é apresentado um modelo baseado na tecnologia da informação analisando-se e comparando-se seus processos associados para, então, definir-se critérios que possam guiar os executivos no projeto dos pro- cessos chaves inerentes ao empreendimento como um todo.

\section{Organização Virtual Inteligente}

Como já foi dito, uma organização virtual é uma quasi-firma criada a partir de ligações digitais entre várias companhias, de tal forma que é praticamente impossível identificar seus limites (Keen, 1991). Essa definição vem de encontro com o cenário do MIT denominado "Pequenas Empresas, Grandes Redes" (Laubacher \& Malone, 1997). Numa organização virtual, o integrador mantem as competências nucleares relativas ao negócio, terceirizando a maioria dos demais processos produtivos. O integrador é responsável por gerenciar as restrições e dependências entre os participantes e seus processos devidos, coordenando as transações entre os parceiros envolvidos.

Segundo Prusak (1997) algumas tendências estão compelindo as empresas a se engajarem em organizações virtuais, tais como:

a) a globalização da economia e a terrível pressão sobre as empresas no que tange à adaptabilidade crescente, inovação e velocidade de produção.

b) a consciência do valor do conhecimento especializado como algo intrínseco a processos e rotinas organizacionais relativos aos nós da organização virtual.

c) a consciência do conhecimento como um fator distinto de produção.

d) baixo preço das redes de computador o que, finalmente, a está transformando em poderosa ferramenta para o trabalho e aprendizado compartilhados.

Durante o desenvolvimento de um empreendimento, dados e informações são trocados entre os atores componentes da organização virtual. 
PRODUÇÃO

Dados e informação não são conhecimento, embora muitas vezes sejam considerados como tal. Há uma grande diferença entre dados, informação e conhecimento.

\section{Dados, Informação e Conhecimento}

Dados representam conjunto de fatos discretos e objetivos sobre eventos, podendo ser entendidos numa organização como registros estruturados de transações (Davenport \& Prusak, 1998).

Informação é dado que faz diferença, ou como diz Peter Drucker "dados com atributos de relevância e propósito". Geralmente informação é entendida como mensagem, geralmente sob a forma de documentos ou mensagens visuais e/ou audíveis. Informação é acima de tudo contextual.

Já conhecimento está ligado à capacidade de agir (Sveiby, 1997). É intuitivo e, portanto, difícil de definir. Está ligado a experiências e valores do usuário, sendo acima de tudo ligado a padrões de reconhecimento, analogias e regras implícitas. $\mathrm{Na}$ maior parte das vezes está, numa organiżação, na mente de seus profissionais - o chamado conhecimento tácito: "Sei que sei, mas não sei como sei" - (Polanyi,1958 e Varela et al.,1992) ou em documentos - o chamado conhecimento explícito -, podendo-se criar mecanismos de transferência de um tipo de conhecimento para outro, conforme explicado no célebre modelo da Espiral do Conhecimento de Nonaka \& Takeuchi, 1995 baseado em: Internalização (explícito para tácito), Externalização (tácito para explícito), Socialização (tácito para tácito) e Combinação (explícito para explícito). Em vista disso, pode-se entender porque há uma grande confusão entre gestão da documentação e gestão do conhecimento.

As seguintes equações podem, portanto, ser usadas (Joia, 1999):

$$
\text { INFORMAÇÃO }=\text { DADO }+\Sigma
$$

(Atributos, Relevância, Contexto)

CONHECIMENTO $=$ INFORMAÇÃO $+\sum$ (Experiência, Valores, Padrões, Regras Implícitas)

\section{Tecnologias da Informação}

O próximo passo é definir-se as tecnologias da informação que devem ser implementadas em uma organização virtual para aumentar sua inteligência. Essas tecnologias são divididas em tecnologias de conectividade, de compartilhamento e de estruturação, segundo a divisão apresentada anteriormente.

\section{Tecnologias de Conectividade}

Como já foi dito, o "grau de alcance" de uma organização virtual é fundamental. Assim, o primeiro passo para se construir uma organização virtual é a escolha correta das tecnologias para conexão dos parceiros. Segundo Badaracco (1991):

" 'O que é um computador? A velha resposta seria uma central de processamento unitária. A nova resposta: o computador é a rede."

Assim, uma infraestrutura baseada numa intranet em cada firma, ligada por extranets à empresa integradora é a solução ideal.

A figura 1 apresenta a infraestrutura necessária.

Para que todos os nós de uma organização virtual sejam ligados, WANs (Wide Area Networks) são necessárias para trabalhar como extranets, permitindo a conexão entre as intranets dos envolvidos. Canais de satélite, fibras óticas, linhas dedicadas, são apenas algumas das formas de se ter um eco-sistema de negócios conectado entre si.

Uma plataforma cliente-servidor é necessária para suportar uma infraestrutura baseada em intranet. Entretanto, alguns problemas podem 


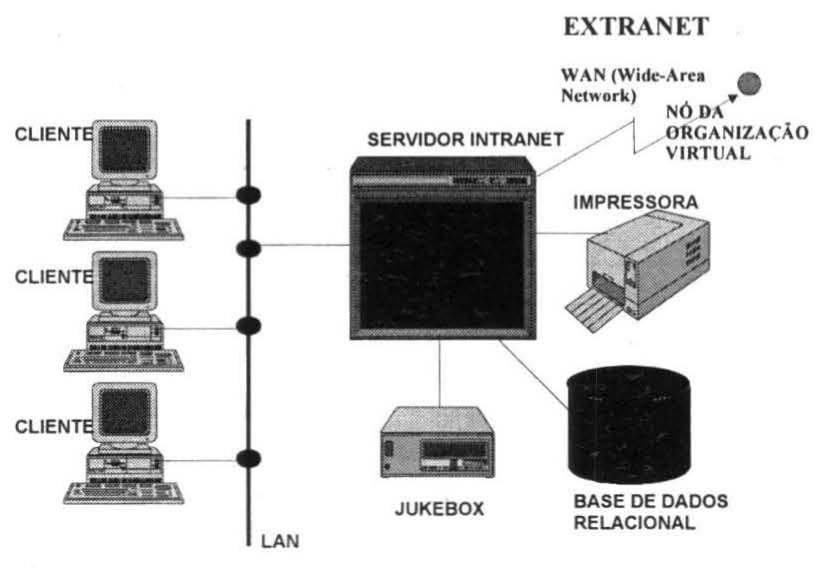

INTRANET

Fig. 1 - Arquitetura Cliente-Servidor Baseada em intranet

surgir para se atingir esse grau de conectividade, como:

a) Para muitas empresas (especialmente as menores) essa infraestrutura é ainda cara, e diferentes protocolos são freqüentemente usados, o que impede a correta comunicação entre as companhias;

b) A infraestrutura de transmissão de dados através dessas ligações digitais é ainda precária e não confiável nos mercados emergentes, como o Brasil.

Todos os dados e informações trocados entre dois ou mais nós da organização virtual devem passar pelo integrador, caso contrário freqüentes problemas de coordenação surgem. Isso, obviamente, diminuirá a flexibilidade, grau de resposta e agilidade dos envolvidos, embora mantenha sob controle processos que seriam naturalmente fragmentados. $\mathrm{O}$ conhecimento derivado desses dados e informações, usado: por um dos nós da organização, pode ser tanto do tipo "documento-a-pessoa" ou "pessoa-apessoa". O primeiro tipo alimenta a "estratégia de codificação" (Hansen et al., 1999), quando o conhecimento explícito é bem mais importante do que o tácito, já que os produtos/serviços gerados pela organização virtual são extremamente padronizados. Já o segundo tipo é importante para a "estratégia de personalização" (Hansen et al., 1999), onde o conhecimento tácito é mais importante do que o explícito, porque os produtos/serviços oferecidos pela organização virtual são "customizados" às necessidades do cliente.

\section{Tecnologias de Compartilhamento}

Durante mais de uma década, as pessoas passaram a usar o computador pessoal pela primeira vez, a maioria para tarefas individuais como criar e/ou revisar um texto ou uma planilha. Atualmente, com o crescimento exponencial do uso de redes, principalmente aquelas baseadas nas potencialidades da Internet, intranet e extranet, o computador passou de máquina de calcular para ferramenta de comunicação. Isso tem permitido pessoas trabalharem num ambiente colaborativo e integrado. Assim, vários softwares têm sido desenvolvidos para:

- permitir o trabalho concorrente de diferen- 
PRODUÇÃO

tes pessoas no mesmo documento;

- permitir o acompanhamento inteligente de mensagens e documentos dentro de um processo produtivo;

- ajudar os empregados a, de forma integrada, ver e manipular informações de modo mais eficiente.

CSCW (Computer Supported Collaborative Work) é, atualmente, uma realidade e pode ser usado em complexos empreendimentos.

O primeiro passo para proporcionar inteligência a uma organização virtual é desenvolver sua conectividade, como foi mostrado acima. $\mathrm{O}$ segundo é permitir que os nós trabalhem de forma cooperativa,e colaborativa, compartilhando dados e informações on-line, em tempo real, de modo a criar o conhecimento coletivo associado ao empreendimento. Existem diversas tecnologias, das mais simples às mais complexas que permitem que tal objetivo seja alcançado. Essas tecnologias são chamadas de forma genérica de groupware.

Dentre as mais importantes tecnologias de groupware podem ser citadas, por exemplo, aquelas baseadas em Internet/intranet, como correio eletrônico, grupos de interesse, listas de discussão, conversas eletrônicas e vídeo-conferências. Essa última tecnologia vem se tornando extremamente relevante para o compartilhamento eficaz do conhecimento tácito, através do processo de socialização face-a-face (Skyrme, 1997). Outras tecnologias de groupware importantes são tando o EDI (Troca Eletrônica de Dados) - que permite às companhias trocar documentos, relatórios etc. em padrões pré-estabelecidos -, quanto a Base de Dados Distribuída que permite aos parceiros obter e compartilhar registros da base de dados, assim como efetuar transações em tempo real entre eles.

Certamente a mais importante tecnologia de compartilhamento é a de Workflow. Os sistemas de Workflow pertencem a uma área mais abrangente: EDMS - Electronic Document Management System (Sistema de Gerenciamento de Documentação Eletrônica).

EDMS não é uma única tecnologia, mas um conjunto delas acopladas para atingir determinado objetivo: o completo controle do ciclo de vida de documentos dentro de uma empresa. As seguintes tecnologias normalmente estão embutidas em um EDMS: Imaging, que trata da necessidade de transformar documentos em papel em mídia digital, através de scanners; Full-Text Search, que recupera documentos buscando palavras dentro dos mesmos; Workflow, que permite a inovação dos processos produtivos através da sua reengenharia, tornando possível o controle da rota de um documento dentro de uma empresa; e Multimídia, a menos desenvolvida das tecnologias EDMS, que permite o armazenamento e recuperação de quadros de animação, sons etc.

A junção de todas essas tecnologias compõe um sistema EDMS completo, ainda hoje bastante raro de ser encontrado no mercado.

\section{Tecnologias de Estruturação}

Não obstante os grandes avanços nas tecnologias de conectividade e compartilhamento, o mesmo não pode ser dito em relação às tecnologias de estruturação. Muito embora alguns avanços tenham sido feitos ultimamente, tais como o desenvolvimento da tecnologia de data mining, essa área é o calcanhar de aquiles para o eficaz desenvolvimento de uma organização virtual inteligente. Estruturação, como foi dito anteriormente, trata da criação de conhecimento a partir de dados e informação. Algumas pesquisas têm mostrado que uma grande carga de informação não leva necessariamente à criação de conhecimento (Joia, 1999), o que é o maior dos problemas hoje enfrentados em complexos empreendi- 
mentos desenvolvidos por organização virtuais. Uma organização virtual é inteligente se e somente se seus nós e respectivos funcionários forem inteligentes, na sua maioria, também.

A habilidade de aprender coisas novas - ou aprender a aprender - é fundamental hoje em dia. Mais, a habilidade de desaprender o que foi aprendido é necessária na maioria das vezes, o que não é um processo de fácil implementação.

Aprender a aprender, habilidade de resolver problemas que nunca foram vistos antes, ser criativo e usar o pensamento indutivo ao invés do dedutivo que ainda forja o nosso sistema educacional, entre outros, são os maiores desafios que os trabalhadores de uma organização virtual se defrontam hoje. Numa organização virtual o integrador deve confiar na capacidade dos seus parceiros para resolverem corretamente os seus problemas devidos. Alguns integradores tomam tal fato como uma premissa básica.
A experiência, no entanto, tem mostrado que o integrador deve estar a par da qualidade do serviço entregue por seus parceiros. Mais recentemente tornou-se evidente para os integradores a necessidade de treinar as outras empresas da organização virtual, ou pelo menos definir padrões e procedimentos que devam ser seguidos para a consecução do projeto. Esse conhecimento explícito é armazenado principalmente em documentos e bases de dados e as principais tecnologias para difundi-los dentro dos nós de uma organização virtual são os Sistemas Especialistas, Data Mining e Sistemas de Instrução Baseada na WEB (IBW).

Os sistemas especialistas são uma importante tecnologia de estruturação, levando os profissionais a um processo de internalização de conhecimento: do conhecimento explícito para o tácito (Nonaka \& Takeuchi, 1995), conforme mostrado a seguir:

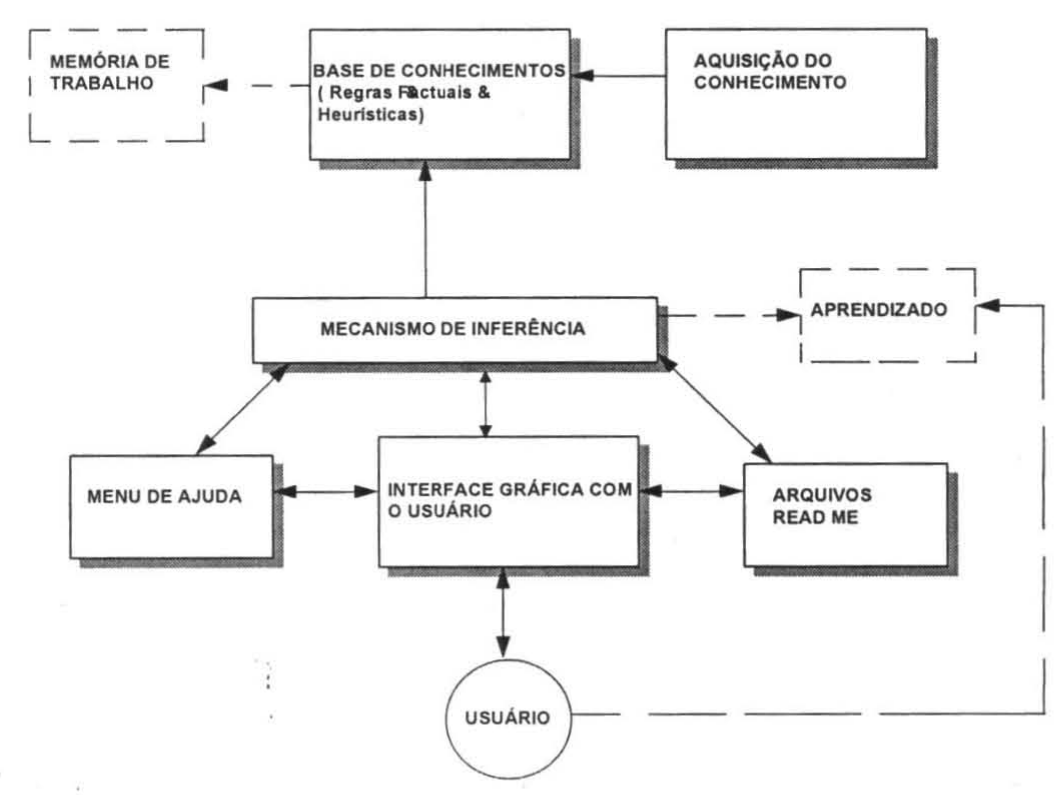

Fig. 2 - Estrutura Básica de um Sistema Especialista 
PRODUÇÃO

Os sistemas especialistas levam aos seguintes benefícios:

1. Aquisição, armazenagem e disponibilização de conhecimento estratégico

2. Disponibilidade, em tempo integral, do conhecimento do especialista

3. Liberação do especialista para resolução de complexos problemas que o sistema especialista não estaria capacitado a resolver

4. Novas técnicas de treinamento que dependem do conhecimento básico de um problema

5. Soluções mais consistentes e qualificadas para um problema, com gasto menor de tempo

6. Padronização de procedimentos operacionais

Sistemas especialistas também chamados de "Sistemas Computacionais Baseados em Conhecimento" devem ser usado com cautela. É importante evitar-se o truque da "máquina inteligente" mas, pelo contrário, conscientizar-se de que tratase de sistema para aumentar a capacidade de pensar do ser humano (Skyrme, 1997).

A tecnologia de Data Mining permite desenvolver formas inteligentes de navegar através de uma grande quantidade de dados e informações, de forma a extrair-se o que é realmente relevante e criar padrões de reconhecimento que impeçam o usuário de sofrer um "overload" de informações desnecessárias. O propósito é o de julgar a relevância da informação para aquele interessado nela. Infelizmente, essa inteligência é ainda baixa, levando o usuário a dispender tempo realizando, ele próprio, os necessários julgamentos e avaliações.

Sistemas de IBW (Instrução Baseada na WEB) são sistemas desenvolvidos de forma a usar as potencialidades da Internet/intranet, de forma a que treinamento corporativo a distância possa ser disponibilizado numa organização virtual, de forma interativa e hipertextual. O usuário necessita usar apenas um browser (Netscape, IExplorer etc.) no

seu computador pessoal. O sistema com o respectivo conteúdo do curso modularizado é armazenado ou no servidor intranet do integrador, ou num servidor Internet genérico.

Sistemas de IBW são compostos de três módulos distintos:

- Módulo de Autoria: usado para criar e disponibilizar automaticamente o conteúdo do curso, pelo autor do mesmo ou outro profissional;

- Módulo de Utilização: usado para processar o treinamento;

- Módulo de Acompanhamento: usado pelo adminisrador do curso para avaliar a performarice dos alunos e coordenar o curso como um todo, através das notas dos alunos, avaliações, problemas encontrados etc. que são armazenados no log do sistema.

Através do uso de um sistema de IBW baseado nos recursos da Internet/intranet e, se possível, acoplado a sistema de vídeo-conferência, vídeo multi-casting e/ou vídeo on-demand, um novo modus-operandi pode ser definido de tal forma que uma "educação just-in-time" ou "educação anytime, anywhere" possam ser disponibilizadas. Esse novo processo é baseado nas seguintes tarefas:

1. Definição e geração do conteúdo programático.

2. Modularização do conteúdo para navegação hipertextual através da WEB.

3. Definição e escolha das seguintes ferramentas:

a) Ferramentas de Comunicação: Correio Eletrônico entre os alunos e dos alunos com o professor, grupo de interesse, lista de discussão, conversas eletrônicas (chats), vídeo-conferências.

b) Ferramentas de Coordenação: Agenda, Novidades, Avaliações, Trabalhos, Exercícios.

c) Ferramentas de Cooperação: Textos, Planilhas, Apresentações, Vídeos, Bibliografia, Papers, Biblioteca Digital. 
4. Disponibilização do conteúdo no sistema através do módulo de autoria.

5. Uso pelos alunos do sistema com o conteúdo disponibilizado, através do módulo de utilização.

6. Avaliação do curso e dos estudantes pelo mentor virtual, através do módulo de gerenciamento.

Todas essas ferramentas podem ser integradas via WEB, inclusive com equipamentos de vídeo-conferência. A maioria dos eventos é assíncrona, sendo apenas o chat e a vídeo-conferência eventos síncronos.
A figura 3 apresenta uma tela de uma sistema de IBW - W ${ }^{3} \mathrm{E}$ (World Wide Web for Education) - desenvolvido pelo autor:

\section{Um Modelo Integrado para Organizações Virtuais Inteligentes}

Para a integração de todas as tecnologias apresentadas anteriormente numa taxonomia estruturada para organização virtuais inteligentes, toma-se como pressuposto que tecnologias são importantes apenas porque permitem a execução

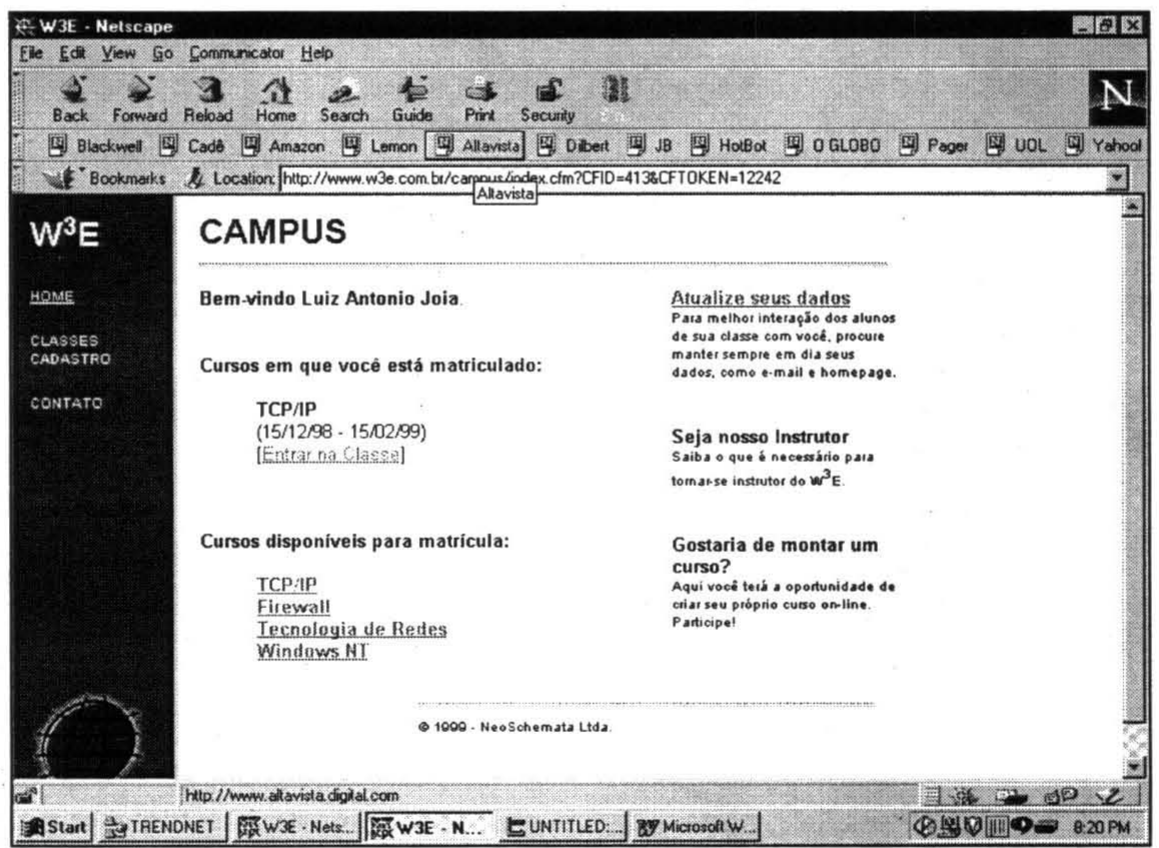

Fig. 3 - Tela de entrada do sistema $W^{3} E$ 
PRODUÇÃO

de serviços, e de que serviços são importantes apenas porque permitem a disponibilização de processos produtivos, segundo a seguinte formulação:

TECNOLOGIAS $\Rightarrow$ SERVIÇOS $=>$ PROCESSOS $=>$ PRODUÇÃO, como mostrado a seguir se já é difícil convencer profissionais dentro de uma empresa a externalizarem seu conhecimento, seja porque eles não sabem como estruturá-lo, seja pela falta de confiança e lealdade à firma, o que dizer de um grupo de profissionais dispersos geograficamente, trabalhando juntos pela primeira vez e pertecendo a diferentes empresas com diferentes culturas?

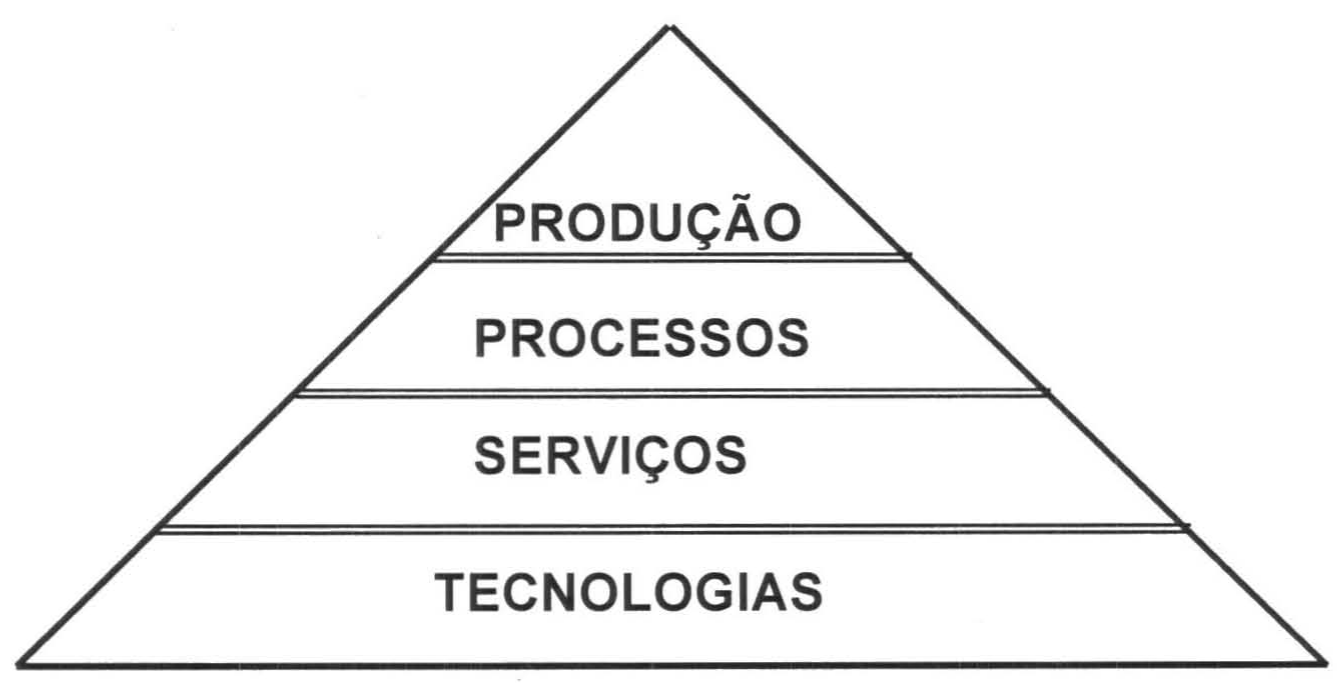

Fig. 4 - Taxonomia do Modelo Integrado

Assim, a tabela seguinte pode detalhar mais precisamente a idéia apresentada na figura 4 , relacionando a Conectividade, Compartilhamento e Estruturação - as três facetas de uma organização virtual inteligente - com os serviços necessários e os processos produtivos existentes dentro de um empreendimento relacional.

\section{Tendências Futuras}

Como foi visto, o conhecimento pode ser tanto explícito quanto tácito. Da mesma forma, a inteligência de uma organização virtual depende da inteligência dos seus nós. Inteligência é a habilidade de usar conhecimento existente para criar conhecimento novo (Drucker, 1998). Mas,
Assim, a primeira tendência é a necessidade de criação pelas empresas de mecanismos de recompensa aos profissionais envolvidos na organização virtual, para externalização do conhecimento estratégico, como já é feito em algumas empresas de consultoria de gestão como a Bain e a Mckinsey (Hansen et al., 1999). Segundo Venkatraman \& Henderson (1998), é importante o desenvolvimento de novas formas de gerenciamento dos recursos humanos, já que as políticas dessa área foram forjadas para trabalhadores administrativos e de produção, concluindose que é necessária a criação de práticas de incentivo e compensação para atrair e manter profissionais do conhecimento. 


\begin{tabular}{|c|c|c|c|}
\hline & CONECTIVIDADE & COMPARTILHAMENTO & ESTRUTURAÇÃO \\
\hline TECNOLOGIAS & $\begin{array}{l}\text { Intranet em Cliente-Servidor, } \\
\text { Extranets, LAN, W AN, } \\
\text { Links de satélites, Links } \\
\text { Dedicados, Rede de fibras } \\
\text { óticas }\end{array}$ & $\begin{array}{l}\text { Internet, Groupware, } \\
\text { Troca Eletrônica de Dados } \\
\text { (EDI), EDMS, Workflow, } \\
\text { Video-Conferência e } \\
\text { Base de Dados Distribuida }\end{array}$ & $\begin{array}{l}\text { Sistemas de Instrução } \\
\text { Baseada na WEB, } \\
\text { Data Mining, } \\
\text { Sistemas Especialistas }\end{array}$ \\
\hline SERVIÇOS & $\begin{array}{l}\text { Link fisico entre os parceiros } \\
\text { (Topologia Estrela com o } \\
\text { Integrador como hub) }\end{array}$ & $\begin{array}{l}\text { Transação de dados e } \\
\text { Informações, } \\
\text { Troca eletrônica } \\
\text { de formulários, } \\
\text { Controle e gestão do } \\
\text { ciclo de vida de } \\
\text { documentos }\end{array}$ & $\begin{array}{l}\text { Educação Anytime, } \\
\text { Anywhere } \\
\text { Educação Just-in-Time, } \\
\text { Aquisição do Conheci- } \\
\text { Mento, Reconhecimento } \\
\text { de Padrões }\end{array}$ \\
\hline PROCESSOS & \multicolumn{3}{|c|}{$\begin{array}{l}\text { INOVAÇÃO DE PRODUTOS; GESTÃO DA OPERAÇÃO; } \\
\text { COORDENAÇÃO DOS PARCEIROS (gerenciamento de restriçðes e dependências); } \\
\text { CONTROLE DE QUALIDADE DOS NÓS DA ORGANIZAÇÃO VIRTUAL }\end{array}$} \\
\hline
\end{tabular}

\section{Produchã}

Tab. 1 - Modelo Integrado para organização virtuais Inteligentes

Uma segunda tendência é usar a tecnologia de forma mais abrangente. Como McKenney et al., 1992 repararam:

\section{"- gerentes usam correio eletrônico para} comunicação eficiente em contextos bem definidos - monitorando o status de tarefas, coordenando esforços, trocando informações factuais, enviando alertas e disponibilizando informações.

- gerentes usam interação face-a-face para definição e discussão de problemas e soluções, construindo um conhecimento compartilhado da situação, discutindo mudanças de prioridades e pressões externas, interpretando sinais ambígüos, e socializando-se com os demais membros."

Novamente, a solução passa pela superação das barreiras organizacionais e culturais, mais do que as tecnológicas. Adicionalmente, a tecnologia deve ser usada para aumentar o emprego do conhecimento tácito, da mesma forma como já o faz para o conhecimento explícito.

A terceira tendência é a homogenização das plataformas tecnológicas, através da definição de uma plataforma "bottom-line", já que um único nó com plataforma inadequada pode impedir a inteligência de uma organização virtual.

Finalmente, a quarta e mais importante tendência é fornecer aos empregados das organização virtuais inteligentes um pensamento digital, de modo a que eles tenham capacidade de estruturação adequada, i.e.: 
PRODUÇ̃̃O

- Tenham habilidade de decodificação e estruturação de dados e informações, tranformandoos em conhecimento;

· identifiquem, enunciem e resolvam problemas;

- detenham os fundamentos para pesquisar, avaliar, criticar e selecionar informações dentro de complexas redes de conhecimento;

- sejam criativos;

- trabalhem em equipe e tenham capacidade de auto-gestão;

- trabalhem em ambientes digitais e, muitas vezes, virtuais.

Assim, investimentos devem ser realizados no desenvolvimento de sistemas de IBW "customizados", de forma a permitir o incremento do capital humano das firmas e, por via de conseqüência, o capital intelectual das organizações virtuais, da mesma forma que desenvolver um ambiente baseado na confiança entre os profissionais, e entre eles e as empresas.

\section{Conclusões}

A organização virtual é um caso limite de organização que desafia nossa compreensão e entendimento de como gerenciar os processos de desenvolvimento do conhecimento através do uso da tecnologia.

Tecnologia, ela própria, não gera nem inteligência nem conhecimento, sendo apenas uma propiciadora para alcançar esse estágio. Não obstante uma enorme variedade de tecnologias da informação já disponíveis para aumentar a conectividade, compartilhamento e estruturação das organizações virtuais, de modo a torná-las inteligentes, os obstáculos maiores ainda existentes, e de não fácil superação, são de natureza organizacional e cultural.
A estratégia de investir fortemente em tecnologia da informação, em detrimento do capital humano pode ser catastrófica. $\mathrm{O}$ perigo reside no fato de que a tecnologia da informação pode acabar por calcificar o conhecimento em algo estático, inerte, desprezando totalmente o fundamental papel do conhecimento tácito.

A economia do conhecimento com os trabalhadores do conhecimento demanda novas formas organizacionais, orgânicas, flexíveis, aparentemente quase anárquicas, mas suficientemente coordenadas de forma a permitir que o conhecimento seja criado, armazenado, recuperado e reutilizado. Desenvolvimentos na recém criada Ciência da Coordenação (Malone \& Crowston, 1994) são fundamentais para o desenvolvimento da inteligência de organizações virtuais em conformidade com o cenário "Pequenas Empresas, Grandes Redes" desenvolvido no MIT (Laubacher \& Malone, 1997) para as organizações do século XXI.

\section{Referências Bibliográficas}

Badaracco, J. (1991). Knowledge Links. In: The Knowledge Link: How Firms Compete Through Strategic Alliances, chapter 5, pp. $107-$ 128, Harvard Business School Press, Boston

Bahrami, H. (1992) - The Emerging Flexible Organization: Perspectives from Silicon Valley, California Management Review, Vol. 34, No. 4

Baker, W. (1994) - Building Intelligent Networks, Networking Smart, chapter 3, McGraw-Hill, Inc.

Davenport, T.H. \& Prusak, L. (1998). Working Knowledge, Harvard Business School Press

Drucker, P. (1998). "From Capitalism to Knowledge Society". In: Neef D. (ed.). The Knowledge Economy, Butterworth-Heinemann, pp. 15-34 
Haeckel, S. \& Nolan, R. (1993). "Managing by Wire", Harvard Business Review, SeptemberOctober, pp. 122-132.

Handy, C. (1997). The Hungry Spirit, Hutchinson, Random House, London

Hansen, M.T., Nohria, N and Tierney T. (1999). What's Your Strategy for Managing Knowledge?, Harvard Business Review, MarchApril, pp. 106-126.

\section{Joia, L.A (1999). "A New Model for} Workers' Retraining in Brazil"- Journal of Workplace Learning, Vol 11 Issue 4, 1999, MCB University Press.

Keen, P. (1991). Shaping the Future, Harvard Business School Press.

Laubacher, R. \& Malone, T. (1997). Two Scenarios for $21^{\text {st }}$ Century Organizations: Shifting Networks of Small Firms or All-Encompassing "Virtual Countries"? , MIT Initiative on Inventing the Organization of the $21^{\text {st }}$ Century, Working Paper 21C WP \#001, Sloan School of Management, MIT

Malone, T. \& Crowston, K. G. (1994). The Interdisciplinary Study of Coordination, $A C M$ Computing Surveys, Vol.26, No.1, March, pp.87119.

Maturana, H.. \& Varela, F.J. (1980) Autopoiesis and Cognition: The Realization of the Living, Reidl, London.

McKenney, J.L., Zack, M.H. and Doherty, V.S. (1992). "Complementary Communication Media: A Comparison of Electronic Mail and Face-to-Face Communication in a Programming Team", In: Nitin Nohria and Robert G. Eccles (eds.), Networks and Organizations: Structure, Form and Action, Chapter 10, Harvard Business School Press, 1992.

Nonaka, I. \& Takeuchi, H. (1995). The Knowledge-Creating Company: How Japanese Companies Create the Dynamics of Innovation, Oxford University Press, New York

Polanyi, M. (1958). Personal Knowledge, Routledge, London
Prusak, L.(1997). "Introduction to Knowledge in Organizations”. In: Prusak L. (ed.). Knowledge in Organizations, ButterworthHeinemann, pp. ix-xv

Skyrme, D. (1997). "From Information to Knowledge Management: Are You Prepared?", Online'97, http://www.skyrme.com/pubs/ on97full.htm

Sveiby, K.E. (1997). The New Organizational Wealth, Berret-Koehler Publishers, Inc.

Varela, F.J., Thompson E., Rosch E. (1992). The Embodied Mind, MIT Press, Cambridge, MA.

Venkatraman, N . \& Henderson, J.C. (1998). "Real Strategies for Virtual Organizing", Sloan Management Review, Fall, Volume 40, $N^{\circ} 1$, pp. 33-48. 